Supporting Information

\title{
Polymersomes via Self-Assembly of Amphiphilic $\beta$-Cyclodextrin- Centered TriArm Star Polymers for Enhanced Oral Bioavailability of Water-Soluble Chemotherapeutics
}

\author{
Mengying Hu, ${ }^{\dagger}$ Yurun Shen, ${ }^{\ddagger}$ Lu Zhang, ${ }^{\dagger}$ and Liyan Qiu ${ }^{*, \neq, \S}$
}

₹ Ministry of Educational (MOE) Key Laboratory of Macromolecular Synthesis and Functionalization, Department of Polymer Science and Engineering, Zhejiang University, 38 Zheda Road, Hangzhou 310027, China

${ }^{\dagger}$ College of Pharmaceutical Sciences, Zhejiang University, 866 Yuhangtang Road, Hangzhou 310058, China

$\S$ Collaborative Innovation Center for Biotherapy, West China Hospital, Sichuan University, Chengdu 610041, China 


\section{Experimental Section}

\subsection{Synthesis of (mPEG-PLA) $)_{3}$-CD Copolymers}

A predetermined amount of mPEG $(\mathrm{Mn}=2000)$, DLLA (weight ratio of mPEG to DLLA: 2/2.5, $2 / 3$ and $2 / 3.5)$ and $0.5 \mathrm{wt} \% \mathrm{Sn}(\mathrm{Oct})_{2}$ were added to a tube for polymerization. The tube was evacuated after $2 \mathrm{~h}$ and sealed. The temperature of the reaction was maintained at $130{ }^{\circ} \mathrm{C}$ for 24 h. The mPEG-b-PLA copolymers with various compositions were purified by redissolving in anhydrous dichloromethane and precipitation in cold diethyl ether twice. mPEG $^{5 \mathrm{k}}-\mathrm{b}-\mathrm{PLA}{ }^{12 \mathrm{k}}$ was synthesized by the method with mPEG $(\mathrm{Mn}=5000)$ and DLLA (weight ration of mPEG to DLLA:3/7).

The predetermined amount of mPEG-b-PLA ( $1 \mathrm{mmol})$, succinic anhydride $(0.120 \mathrm{~g}, 1 \mathrm{mmol})$, DMAP $(0.122 \mathrm{~g}, 1 \mathrm{mmol})$, and triethylamine (TEA; $0.140 \mathrm{~mL}, 1 \mathrm{mmol})$ were dissolved in anhydrous dioxane and stirred for $24 \mathrm{~h}$ at room temperature. Dioxane was evaporated under reduced pressure and the product was precipitated in ethyl ether twice. After drying in vacuum overnight, white powder of mPEG-PLA-COOH was obtained.

$\beta$-CD (1.135 g, $1 \mathrm{mmol}), \mathrm{CDI}(0.649 \mathrm{~g}, 4 \mathrm{mmol})$, and TEA $(0.14 \mathrm{~mL}, 1 \mathrm{mmol})$ were dissolved in dry dimethyl sulphoxide (DMSO) and reacted at room temperature for $3 \mathrm{~h}$. The reaction was undertaken under nitrogen and in dark conditions. Then, mPEG-PLA-COOH (4 mmol) was added dropwise to the system slowly. After reacting overnight, the product (mPEG-PLA) ${ }_{3}$-CD was precipitated twice in cold ethyl ether and further purified by dissolving in acetone, dialyzing against water for 2 days, and lyophilization.

\subsection{Preparation of Polymersomes}

$2 \mathrm{~mL} \mathrm{DOX} \cdot \mathrm{HCl}$ aqueous solution $(1 \mathrm{mg} / \mathrm{mL})$ was injected into $3 \mathrm{~mL}$ acetone containing various amount of (mPEG-PLA) $)_{3}-\mathrm{CD}$ or $\mathrm{mPEG}^{5 \mathrm{k}}-\mathrm{b}-\mathrm{PLA}^{12 \mathrm{k}}$ according to different drug loading 
content under magnetic stirring. The organic solvent was eliminated by evaporation under vacuum at $35{ }^{\circ} \mathrm{C}$ to obtain a polymersome solution. The unencapsulated free $\mathrm{DOX} \cdot \mathrm{HCl}$ was removed through dialysis using a membrane (MWCO: 8000-14000 Da, supplied by Minnesota Mining and Manufacturing Company, USA) for $8 \mathrm{~h}$. Finally, DOX $\bullet \mathrm{HCl}$ loaded polymersomes were collected by freeze-drying. The blank polymersomes were prepared in the same way except that drugs were eliminated.

\subsection{Preparation of fluorescent dyes-loaded Polymersomes}

$1 \mathrm{~mL}$ Dextran-FITC aqueous solution $(0.5 \mathrm{mg} / \mathrm{mL})$ was injected into $1.5 \mathrm{~mL}$ acetone containing $10 \mathrm{mg}\left(\mathrm{mPEG}^{2 \mathrm{k}}-\mathrm{PLA}^{3 \mathrm{k}}\right)_{3}-\mathrm{CD}$ and $0.1 \mathrm{mg}$ DiI under magnetic stirring. The organic solvent was eliminated by evaporation under vacuum at $35^{\circ} \mathrm{C}$ to obtain a dual fluorescent dyesloaded polymersome solution. The unencapsulated dyes was removed through dialysis using a membrane (MWCO: 8000-14000 Da, supplied by Minnesota Mining and Manufacturing Company, USA) for $8 \mathrm{~h}$.

\subsection{Cell Cytotoxicity Assay}

MDCK cells were seeded in 96-well culture plates at a density of 5000 cells/well and grown for $24 \mathrm{~h}$ under the condition of $5 \% \mathrm{CO}_{2}$ at $37{ }^{\circ} \mathrm{C}$. The medium was then added with free $\mathrm{DOX} \cdot \mathrm{HCl}$ and $\mathrm{Ps}-\mathrm{DOX} \cdot \mathrm{HCl}$ in the concentration range of $3.1-50 \mu \mathrm{g} / \mathrm{mL}$ for $2 \mathrm{~h}$ at $37{ }^{\circ} \mathrm{C}$. Then, $32 \mu \mathrm{L}$ of MTT solution ( $5 \mathrm{mg} / \mathrm{mL}$ in PBS) was added into each well followed by $4 \mathrm{~h}$ incubation at $37{ }^{\circ} \mathrm{C}$ in darkness, after which, the medium was removed and $200 \mu \mathrm{L}$ DMSO was added. Measurement was performed using Multiskan MK3 (Thermo, USA) at $570 \mathrm{~nm}$. Cell viability of the control group was considered as $100 \%$. Relative viability was calculated by comparing the absorbance intensity of groups treated with different drug-loaded micelles with the control group. 
The drug concentration of inhibition of $50 \%$ cell growth $\left(\mathrm{IC}_{50}\right)$ was calculated by SPSS 18.0. All experiments were in triplicate, the results are given as mean \pm standard deviation.

\subsection{Cellular Uptake Investigation}

For quantitative study, MDCK cells were seeded at a density of $1 \times 10^{5}$ cells/well into a 12 -well culture plate and allowed to attach for $24 \mathrm{~h}$ until confluence. The medium was then removed and treated with fresh MEM containing free R123, Ps-R123, free DOX $\cdot \mathrm{HCl}$ and Ps-DOX $\cdot \mathrm{HCl}(5$ $\mu \mathrm{g} / \mathrm{mL}$ ) at $37{ }^{\circ} \mathrm{C}$ for $2 \mathrm{~h}$. After incubation, the cells were washed with PBS, detached with trypsin-EDTA and resuspended in proper volume of PBS for flow cytometer analysis (Beckman Coulter, FC500MCL, US). Data from 10000 events were gated using forward and side scatter parameters to exclude debris and dead cells as well as control cells incubated with media alone as control for autofluorescence. All experiments were conducted in triplicates and data presented as means \pm standard deviation.

The internalization of free $\mathrm{DOX} \cdot \mathrm{HCl}$ and $\mathrm{Ps}-\mathrm{DOX} \cdot \mathrm{HCl}$ by MDCK cells was also monitored by a confocal laser scanning microscope. (CLSM, Nikon A1, Japan). When MDCK cells cultured in sterile cover slips met the requirement of $80 \%$ confluence, $20 \mu \mathrm{g} / \mathrm{mL}$ fresh MEM dispersion of free $\mathrm{DOX} \cdot \mathrm{HCl}$ or Ps-DOX $\bullet \mathrm{HCl}$ was added and incubated for 5 min, 15 min, 30 min, $60 \mathrm{~min}, 90 \mathrm{~min}$ and $120 \mathrm{~min}$, respectively. In the end of incubation, cells were rinsed with cold PBS, fixed by 4\% paraformaldehyde and treated by Hoechst 33258 to stain the nuclei. The cells were finally sealed with glycine/PBS ( $\mathrm{v} / \mathrm{v}=1: 1)$ and observed by a confocal microscopy system.

\subsection{In vivo Antitumor Activity}

The in vivo inhibitory efficacy of free $\mathrm{DOX} \cdot \mathrm{HCl}$ and $\mathrm{Ps}-\mathrm{DOX} \cdot \mathrm{HCl}$ via different adminstration was evaluated against S180 solid tumor bearing mice model. After S180 cells being 
subcutaneously implanted into the armpits of the mice, the tumor bearing mice were randomly divided into six groups (5 mice per group): group 1, control (normal saline); group 2, intravenous injection with free DOX $\cdot \mathrm{HCl}(2 \mathrm{mg} / \mathrm{kg})$; group 3, oral gavage with free DOX $\cdot \mathrm{HCl}(10 \mathrm{mg} / \mathrm{kg})$; group 4, oral gavage with free $\mathrm{DOX} \cdot \mathrm{HCl}(20 \mathrm{mg} / \mathrm{kg})$; group 5, oral gavage with Ps-DOX $\bullet \mathrm{HCl}$ $(10 \mathrm{mg} / \mathrm{kg})$; group 6, oral gavage with Ps-DOX $\cdot \mathrm{HCl}(20 \mathrm{mg} / \mathrm{kg})$. The dose schedule started when the tumor volume was about $100-200 \mathrm{~mm}^{3}$ (5 days after implantation) and treatments were given five times every day. Body weight was monitored daily while tumor size was determined every alternate day. Tumor volume was calculated as the following:

$$
\mathrm{V}=\left[\text { length } \times(\text { width })^{2}\right] / 2
$$

On the day 14 , the animals were sacrificed by cervical dislocation, and the tumor mass was harvested, weighted, photographed, and processed for histopathological examination. The tumor inhibition rate (TIR\%) was calculated according to the formula:

$$
\text { TIR } \%=\frac{\text { Wcontrol-Wtreated }}{\text { Wcontrol }} \times 100 \%
$$

$\mathrm{W}_{\text {control }}$ and $\mathrm{W}_{\text {treated }}$ represented the tumor weights from the control group and various treatment groups.

\subsection{Statistical analysis}

Data were expressed as mean \pm SD and statistically analyzed using the one way analysis of variance (ANOVA). A significant difference was considered as $\mathrm{p}<0.05$, and very significant difference was regarded as $\mathrm{p}<0.01$. 


\section{Supplementary Figures}
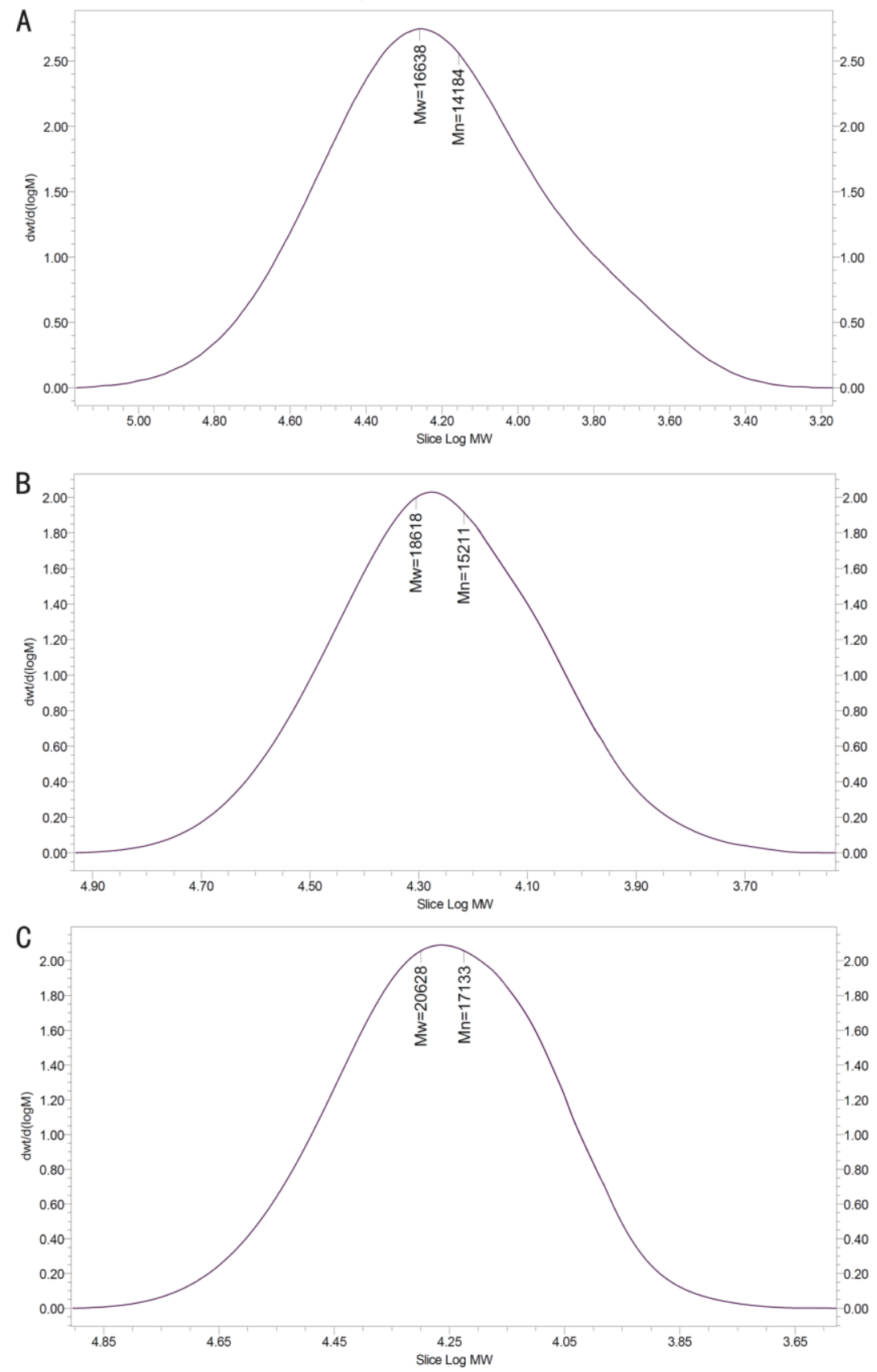

Figure S1. GPC chromatogram of (A) $\left(\mathrm{mPEG}^{2 \mathrm{k}}-\mathrm{PLA}^{2.5 \mathrm{k}}\right)_{3}-\mathrm{CD},(\mathrm{B})\left(\mathrm{mPEG}^{2 \mathrm{k}}-\mathrm{PLA}^{3 \mathrm{k}}\right)_{3}-\mathrm{CD},(\mathrm{C})$ $\left(\mathrm{mPEG}^{2 \mathrm{k}}-\mathrm{PLA}^{3.5 \mathrm{k}}\right)_{3}-\mathrm{CD}$ using THF as solvent. 

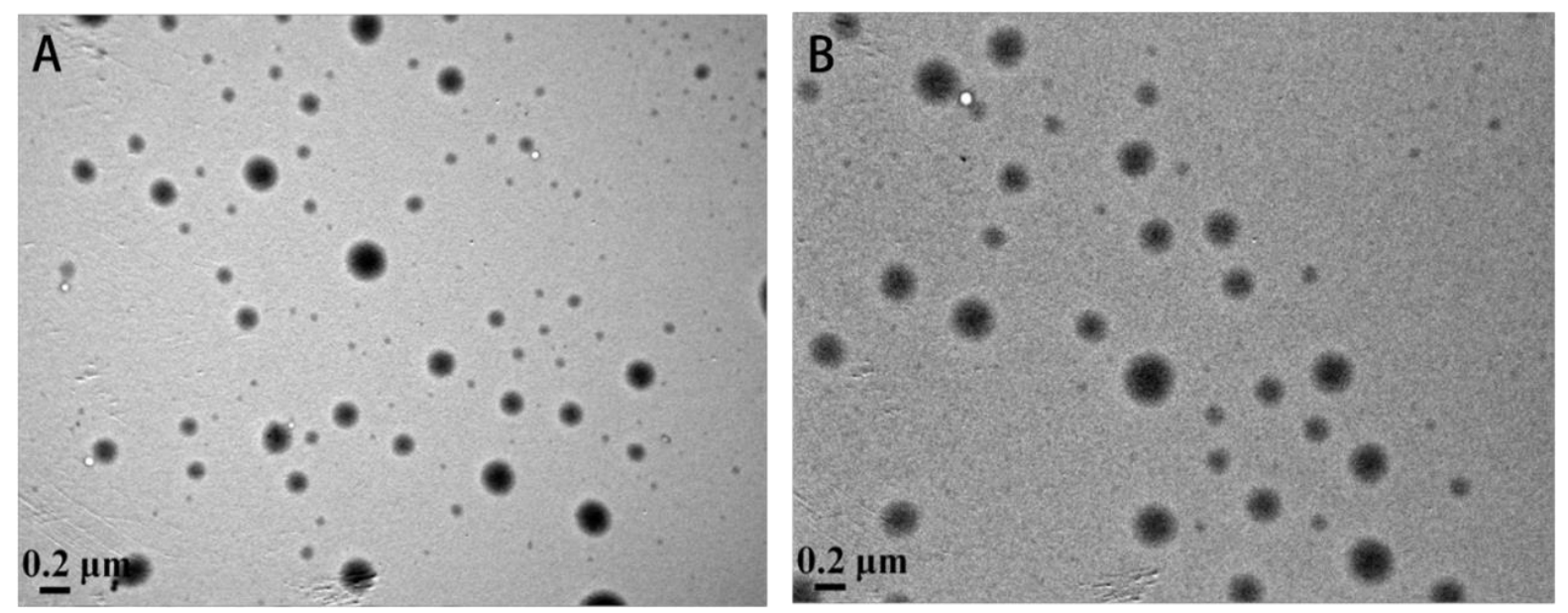

Figure S2. TEM images of blank nanoparticles self-assembled by $(A)\left(\mathrm{mPEG}^{2 \mathrm{k}}-\mathrm{PLA} \mathrm{A}^{2.5 \mathrm{k}}\right)_{3}-\mathrm{CD}$ and $(\mathrm{B})\left(\mathrm{mPEG}^{2 \mathrm{k}}-\mathrm{PLA}^{3.5 \mathrm{k}}\right)_{3}-\mathrm{CD}$.
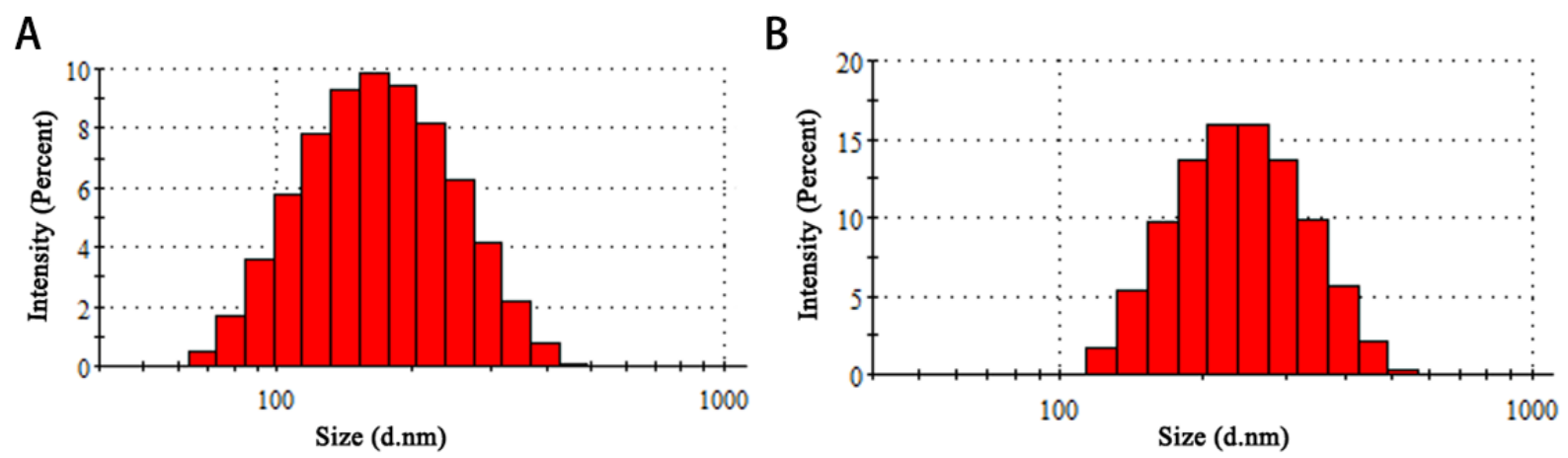

Figure S3. Size distribution of (A) blank $\left(\mathrm{mPEG}^{2 \mathrm{k}}-\mathrm{PLA}^{3 \mathrm{k}}\right)_{3}-\mathrm{CD}$ polymersomes and (B) $\mathrm{DOX} \cdot \mathrm{HCl}-$ loaded polymersomes $(\mathrm{Ps}-\mathrm{DOX} \cdot \mathrm{HCl})$. 


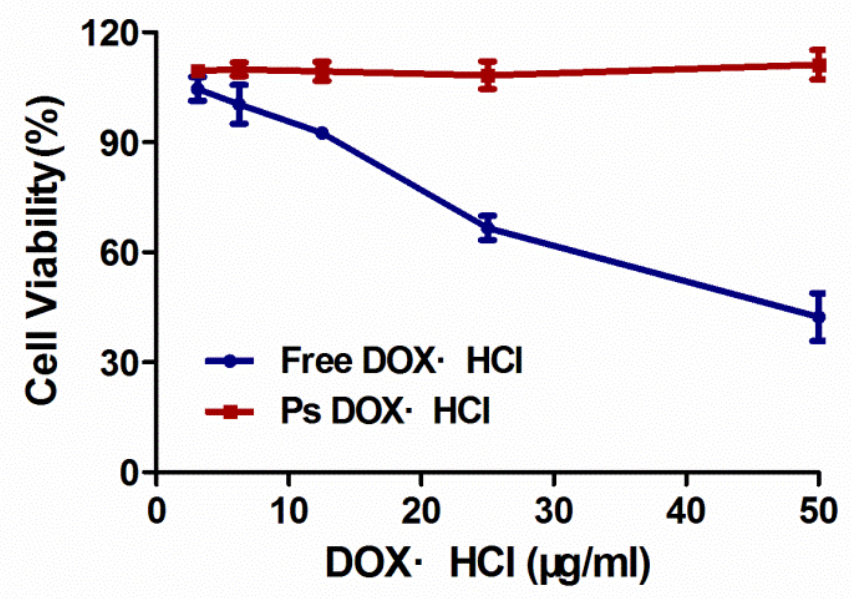

Figure S4. Relative viability of MDCK cells incubated with free $\mathrm{DOX} \cdot \mathrm{HCl}$ and $\mathrm{Ps}-\mathrm{DOX} \cdot \mathrm{HCl}$ for $2 \mathrm{~h}$. All data represent as mean $\pm \mathrm{SD}(\mathrm{n}=3)$.

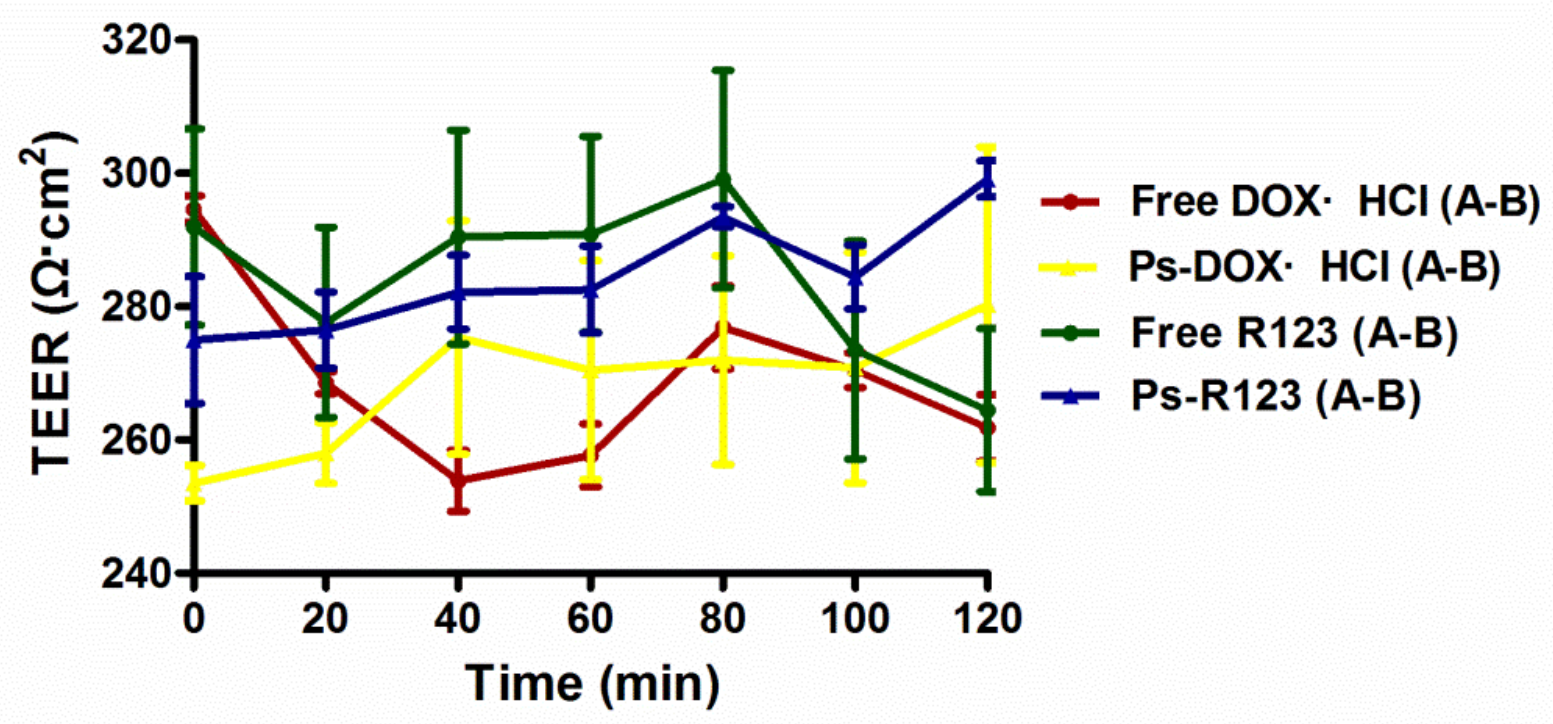

Figure S5. TEER vs time profiles observed for free DOX $\cdot \mathrm{HCl}$, Ps-DOX $\cdot \mathrm{HCl}$, free $\mathrm{R} 123$ and PsR123 at $37^{\circ} \mathbf{C}$. 


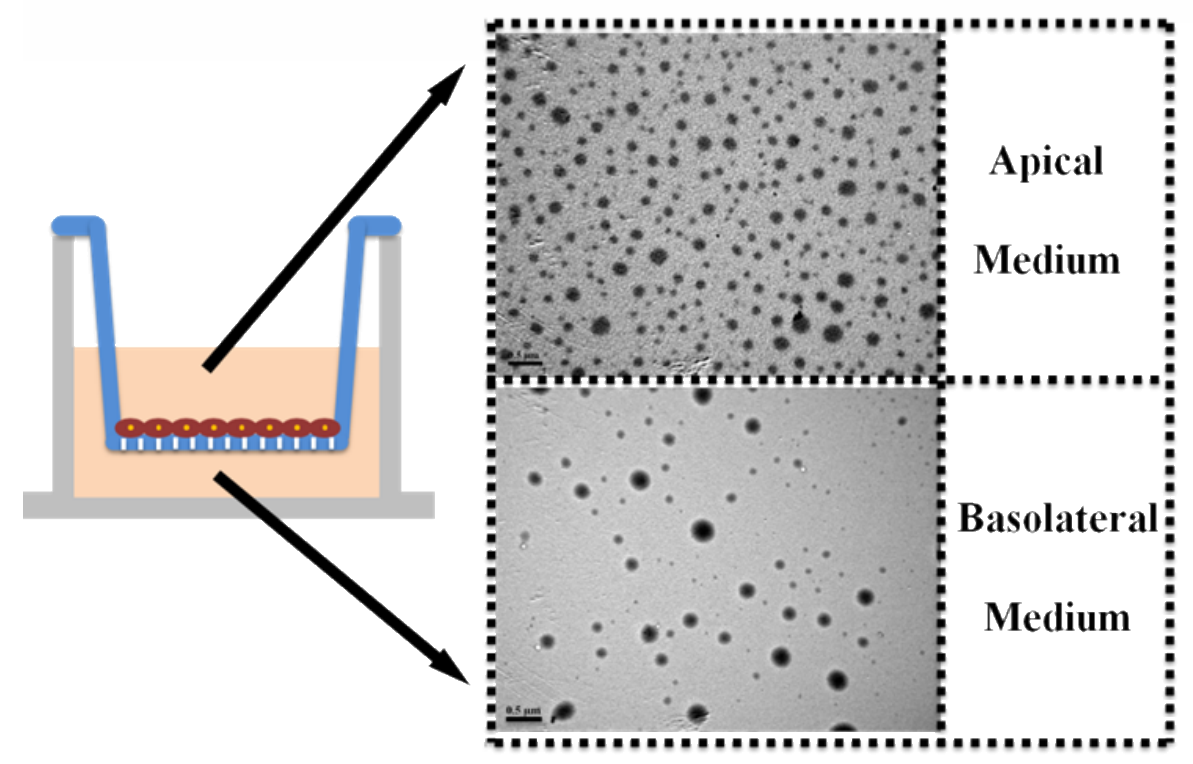

Figure S6. TEM images of apical and basolateral medium after incubation of Transwell filter grown MDCK cell monolayer with Ps-DOX $\cdot \mathrm{HCl}$ at $37^{\circ} \mathrm{C}$ for $2 \mathrm{~h}$. Bar $=0.5 \mu \mathrm{m}$. 